\title{
Cone-beam computed tomography analysis of the vestibular surgical pathway to the palatine root of the maxillary first molar
}

\author{
Atakan Kalender ${ }^{1}$ \\ Umut Aksoy' \\ Fatma Basmaci ${ }^{1}$ \\ Kaan Orhan² \\ Ayse Isil Orhan ${ }^{3}$
}

\section{ABSTRACT}

Objective: The aim of this study was to evaluate the anatomical distance between apices of the palatine root of the maxillary first molars to the buccal bone plate to identify the vestibular surgical pathway in a Turkish adult population using cone-beam computed tomography (CBCT) images.

Methods: CBCT scans of 107 ( 48 male and 59 female) patients were retrospectively analyzed. The overall mean age was 38.6 years. The distance between the vestibular cortex and vestibular side of the palatine root was measured for 192 maxillary first molars both on axial images parallel to the palatal plane and on reformatted cross-sectional images. A Pearson's chi square test and MannWhitney U-test were performed to evaluate differences among age, localization, and measurements. Differences were considered statistically significant at $P<.05$.

Results: The mean distance between the buccal cortex and the buccal side of the palatine root of the superior first molar in both male and female patients was 10.13 and $9.70 \mathrm{~mm}$, respectively. The incidence of interposition of the lateral recess of the maxillary sinus between the roots was $42.2 \%$ and $49 \%$ in men and women, respectively. Statistically significant sex-related differences were found in the vestibular surgical pathway $(P<.05)$.

Conclusions: For precise planning of endodontic surgery, it is crucial to determine the exact dimensions and location of the periapical lesion, as well as its relationship with the roots and other neighboring anatomical structures. CBCT can be a powerful tool for the evaluation of surgical cases in three dimensions with less ionizing radiation and better avoidance of complications during surgery. (Eur J Dent 2013;7:35-40)

Key words: CBCT; endodontic surgery; vestibular surgical pathway; palatine root

1 Department of Endodontics, Near East University, Faculty of Dentistry, Mersin 10, TURKIYE

2 Department of Dentomaxillofacial Radiology, Near East University, Faculty of Dentistry, Mersin 10, TURKIYE ${ }^{3}$ Division of Pediatric Dentistry, Ministry of Health, 75th Year Ankara Oral and Dental Health Centre, Ankara, TURKIYE
- Corresponding author: Dr. Umut Aksoy

Near East University, Faculty of Dentistry Department of Endodontics, Mersin 10, TURKIYE

Tel: +903926802030

Fax: +9039268020 25

Email: dtumutaksoy@ggmail.com 


\section{INTRODUCTION}

Conventional nonsurgical endodontic treatment has a high degree of clinical success, but surgical intervention becomes necessary in certain cases. The aim of surgery is to eliminate infected tissues by resecting the diseased root apex and sealing the root tip with a retrograde filling, thus allowing the tissues to heal. ${ }^{1,2}$ Although this surgical procedure has been considered difficult to perform for the maxillary molars, particularly for the palatine root, surgical endodontic treatment for the palatine root of the maxillary molars has been shown to be decisive and strategic to avoid root amputation or extraction. ${ }^{3,4}$

The operative site is frequently close to important anatomical structures, such as the major palatine vascular-nervous bundle and the maxillary sinus. ${ }^{5}$ According to Wallace, ${ }^{6}$ the latter lies between the roots of the first and second superior molars in $40 \%$ of cases. The buccal roots of the maxillary molars are generally situated between the anterolateral surface of the sinus and the outer alveolar plate, whereas the palatal roots are between the base of the sinus and the palatine plate of the maxilla. ${ }^{7,8}$ With palatal access to this area, perforations of the maxillary sinus, iatrogenic sinusitis, and damage to the major palatine artery and/or the major palatine nerve may occur. Clear visualization of the operative area as well exact localization of the anatomic structures surrounding the area before surgery is therefore crucial to prevent surgical complications. The advent of three-dimensional (3D) imaging has provided endodontists with tools that were not previously available to clinicians, and has facilitated interactive image manipulation and enhancement to visualize the area of interest in 3D. Cone-beam computed tomography (CBCT) is a $3 \mathrm{D}$ imaging modality that has been specifically designed to produce undistorted 3D information of the maxillofacial skeleton, including the teeth and their surrounding tissues, with a significantly lower effective radiation dose as compared with conventional $\mathrm{CT}^{9-13}$ With proper knowledge of root anatomy and the $3 \mathrm{D}$ interrelations of roots and the maxillary sinus, a safer surgical intervention can be performed, especially in the areas involving important anatomic structures, such as the maxillary sinus and inferior alveolar nerves. ${ }^{11}$

The aim of this study was to evaluate the anatomical distance between apices of the palatine root of the maxillary first molars to the buccal bone plate to identify the vestibular surgical pathway in two different age groups in a Turkish adult population using reconstructed 3D CBCT images.

\section{MATERIALS AND METHODS}

Data from CBCT examinations of 214 sites in 107 ( 48 male, 59 female) patients referred to our outpatient clinic were retrospectively analyzed. The overall mean age was 38.6 years [range, $18-81$ years; standard deviation (SD), 15.8 years]. Informed consent was obtained from all patients before CBCT examinations. Subjects with evidence of bone disease (especially osteoporosis), relevant drug consumption, skeletal asymmetries, or trauma were excluded from the study. There was no preference regarding sex with respect to patient choice; however, only patients from our native population were included in the study. Only high-quality scans were included. Low-quality images, such as those with scattering or insufficient accuracy of bony borders, were excluded.

\section{Imaging using CBCT}

CBCT scans (NewTom 3G; Quantitative Radiology s.r.l., Verona, Italy) that included the entire maxillary anatomy were used in this study. To avoid motion artifact, every CBCT scan was standardized according to a strict scanning protocol. Patients were placed in a horizontal position, stabilized with custom-made head bands and chin support, and monitored to ensure that they remained motionless throughout the duration of the scan (36 s). The CBCT image parameters were as follows: the axial slice thickness was $0.3 \mathrm{~mm}$ and the voxels were isotropic. All images were recorded at $120 \mathrm{kVP}$ and 3 to $5 \mathrm{~mA}$ using a 9-inch field of view, an axial slice thickness of $0.3 \mathrm{~mm}$, and isotropic voxels. Radiographic parameters $(\mathrm{kV}, \mathrm{mA})$ were determined automatically from scout views by the NewTom 3G. Depending on the size of the patient and the extent of beam attenuation, exposure varied up to $40 \%$. All constructions were performed on a 21.3-inch flatpanel color-active matrix thin-film transistor (TFT) medical display (Nio Color 3MP; Barco, Belgium) with a resolution of $2048 \times 1536$ pixels at $76 \mathrm{~Hz}$ and $0.2115-\mathrm{mm}$ dot pitch operated at 10 bits.

Image evaluation

All CBCT images were retrospectively evaluated by a single observer. Axial, sagittal, cross-section- 
al, and panoramic images were reconstructed for all semi-maxillae, and $3 D$ reconstructions were used as necessary (Figure 1). A specific function of the management software that enables values in millimeters to be obtained for lines traced directly on the images was used to measure the distance between the vestibular cortex and vestibular side of the palatine root.

Measurements were performed on 192 maxillary first molars both on axial images parallel to the palatal plane and on reformatted cross-sectional images perpendicular to the mesiodistal axis of the tooth arch. Reference points for tracing measurement lines were as follows: 1) point $(P)$ on the buccal side of the palatine root $2 \mathrm{~mm}$ below the apex and 2) the corresponding point on the vestibular cortex, between the two vestibular roots (BC).

Statistical analyses were performed using the SPSS software (ver. 12.0.1; SPSS, Inc., Chicago, IL, USA). Wilcoxon matched-pairs signed-ranks tests were used to assess the intraobserver reliability of repeated measurements and examinations. Differences according to sex and sites were evaluated using chi-square tests, and measurements of the distance between the apex of the palatine root of the maxillary first molar to the buccal bone plate were evaluated using Mann-Whitney U-tests. Differences were considered statistically significant when $p<0.05$.

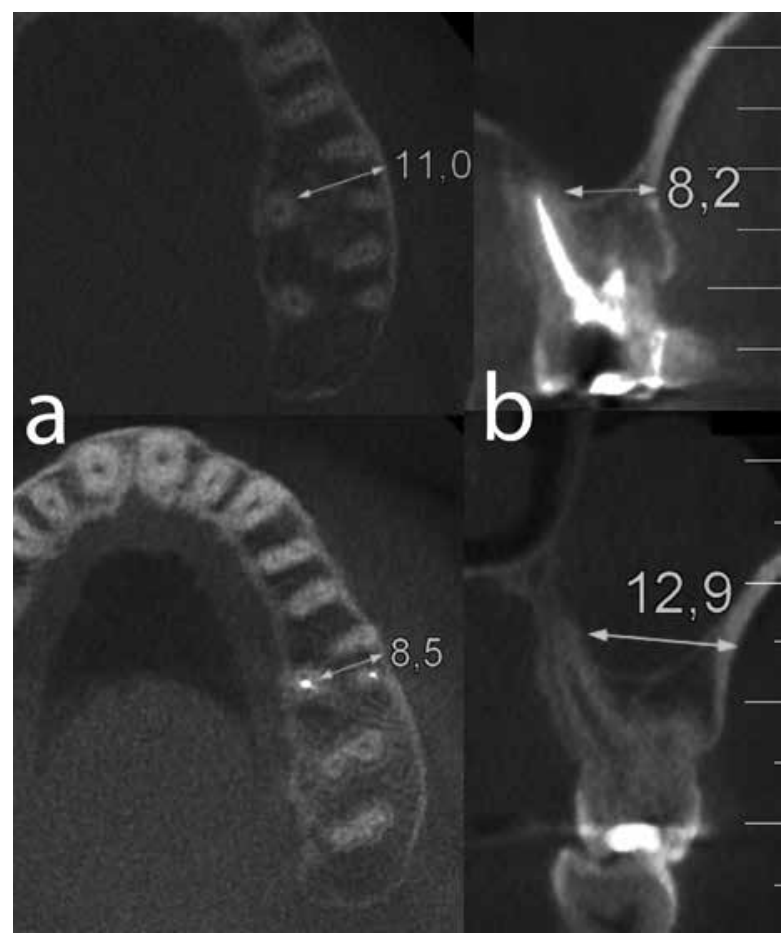

Figure 1. (a) showing actual measurements on axial and (b) reformatted cross-sections by means of the software of the machine.

\section{RESULTS}

Repeated measurement of CBCTs indicated no significant intraobserver differences ( $P>$.05). Intraobserver consistency was rated at $96.4 \%$ between two measurements. CBCT analysis revealed that the mean value of the distance between the buccal cortex and the buccal side of the palatine root of the maxillary first molar in male and female patients was 10.13 and $9.70 \mathrm{~mm}$, respectively (total, $9.90 \mathrm{~mm}$; range, 6.6-14.8 mm). There was a statistically significant difference in the distance between the vestibular cortex and vestibular side of the palatine root between males and females $(P=$.027) (Table 1).

The incidence of interposition of the lateral recess of the maxillary sinus between the roots was $42.2 \%$ and $49 \%$ in men and women, respectively (45.8\% in overall measurements) (Table 2). In female patients, the incidence of interposition of the lateral recess of the maxillary sinus between roots was higher, but statistical significance was not observed $(P=.345)$.

With respect to age groups, measurements in patients 18 to 54 years of age were slightly higher than those in patients 55 years of age and older (Table 1), but statistical significance was not observed $(P=.061)$. The incidence of interposition of the lateral recess of the maxillary sinus between the roots was significantly higher in patients 18 to 54 years of age $(58.4 \%)$ than in patients 55 years of age and older (27.8\%) (P=.001) (Table 2).

\section{DISCUSSION}

Surgical intervention may be require for some clinical conditions that are refractory to conventional endodontic treatment. ${ }^{14-17}$ However, because of the close proximity of the maxillary molar teeth to the maxillary sinus, investigation of the operative area before surgery is crucial. A thorough history, clinical examination, and high-quality periapical radiographs are essential18 for preoperative diagnosis of teeth referred for apical surgery. However, periapical radiography is limited by the fact that information is rendered in only two dimensions. ${ }^{19}$

Because periapical radiographs are 2D images of 3D structures, superimposition of adjacent structures may obscure the visibility of teeth and surrounding structures. CBCT produces a coneshaped X-ray beam, and this makes it possible to 
capture the image in a single exposure rather than capturing the slices separately as in multi-detector CT (MDCT). The most important advantage of this imaging modality is acquiring comparable images with a much lower radiation dose than MDCT.9-13 In recent studies, it was concluded that CBCT scans are more accurate than periapical radiographs and are effective and safe for the detection of dentoalveolar structures. ${ }^{10,20}$

According to the results of this study, the mean value of the distance between the buccal cortex and the buccal side of the palatine root of the maxillary first molar was $9.9 \mathrm{~mm}$, which was comparable with the results of Rigolone's study, ${ }^{5}$ in which it was $9.73 \mathrm{~mm}$. In the maxillary first molar teeth in Huumonen's study ${ }^{21}$ the distance was $9.6 \mathrm{~mm}$. In another study by Jin et $\mathrm{al}^{22}$ the thickness from the palatal root to the buccal bone plate was 10.69 $\mathrm{mm}$.

In terms of differences between males and females in this study, the male group showed thicker bone measurements as compared with females (10.13 and 9.70, respectively). Jin et al ${ }^{22}$ also found thicker bone plates in men than in women, but did not recommend different apical surgery protocols for men and women. This disparity, which was statistically significant in this study, can be explained by skeletal size differences between the sexes.

The present study also showed that the sinus floor was interposed between the palatal and buc- cal roots of the maxillary first molars in $45 \%$ of patients. This value was larger than that found by Rigolone et $a l,{ }^{5}$ who found the maxillary sinus to be located between the buccal and palatal roots of the maxillary first molars in $25 \%$ of patients using CBCT. On the other hand, Huumonen et $\mathrm{al}^{21}$ and Low et $\mathrm{al}^{19}$ found larger values for maxillary molar teeth $(62 \%$ and $76 \%$, respectively). In terms of differences between age groups, the maxillary sinus was interposed more often in patients aged 18 to 54 years than in patients aged 55 years and older. Previous studies ${ }^{23,24}$ reported that the volume of the maxillary sinus decreases as a result of aging, and this may explain our results. The decrease in volume may be caused by the loss of minerals in the bone matrix of all bony structures that surround the maxillary sinus in all directions; these structures contact the maxillary sinus, and their loss of minerals decreases the maxillary sinus volume. ${ }^{23,25,26}$

Because apical surgery normally involves a labial or buccal approach, the thickness of the buccal bone plate is an important factor in terms of reaching the apex and securing the surgical field, especially in the case of maxillary molars. Periapical surgery of the palatine root of the maxillary molar teeth is considered difficult because of the complexity and variability of the anatomic structures, such as the major palatine vascular-nervous bundle and the maxillary sinus. In addition,

Table 1. Measurement of the vestibular surgical pathway on cone-beam computer tomography (CBCT) images according to age and sex.

\begin{tabular}{|c|c|c|c|c|c|}
\hline \multicolumn{2}{|l|}{ Sex/Age } & $\mathrm{n}$ & Mean distance & S.D. & $\mathrm{p}$ value \\
\hline Female & & 102 & 9,7 & 1,3 & \multirow{2}{*}{$0.027 *$} \\
\hline Male & & 90 & 10,13 & 1,36 & \\
\hline Age & $18-54$ & 113 & 10,1 & 1,4 & 0.061 \\
\hline
\end{tabular}

$\mathrm{n}$ indicates number, s.d. Standard deviation, ${ }^{*}$ Statistical significant

Table 2. Incidence of interposition of the lateral recess of the maxillary sinus between the roots according to age and sex.

\begin{tabular}{|c|c|c|c|c|c|c|c|c|}
\hline \multirow[t]{3}{*}{ Sex/Age } & \multicolumn{8}{|c|}{$\begin{array}{l}\text { Incidence of interposition of the lateral recess of the maxillary sinus between the roots accord- } \\
\text { ing to age and sex }\end{array}$} \\
\hline & \multirow[b]{2}{*}{$\mathrm{n}$} & \multirow[b]{2}{*}{$\%$} & \multicolumn{2}{|c|}{+} & \multicolumn{2}{|c|}{ Total } & \multirow[t]{2}{*}{$p$ value } & \\
\hline & & & $\mathrm{n}$ & $\%$ & $\mathrm{n}$ & $\%$ & & \\
\hline Female & & 52 & 51 & 50 & 49 & 102 & 100 & \multirow{3}{*}{0.345} \\
\hline Male & & 52 & 57,8 & 38 & 42,2 & 90 & 100 & \\
\hline Total & & 104 & 54,2 & 88 & 45,8 & 192 & 100 & \\
\hline \multirow{2}{*}{ Age } & $18-54$ & 47 & 41,6 & 66 & 58,4 & 113 & 100 & \multirow{3}{*}{$0.001 *$} \\
\hline & $55+$ & 57 & 72,2 & 22 & 27,8 & 79 & 100 & \\
\hline Total & & 104 & 54,2 & 88 & 45,8 & 192 & 100 & \\
\hline
\end{tabular}

$\mathrm{n}$ indicates number, s.d. Standard deviation, ${ }^{*}$ Statistical significant 
problems with vision and access to the palatine root have discouraged endodontic surgery. However, with improved equipment and instrumentation such as microsurgical loupes and microscopes, fiber optics, micromirrors, ultrasonic root-end preparation, and CBCT, many of these difficulties are reduced. 5,21,27 Rigolone et $\mathrm{al}^{5}$ suggested a less invasive vestibular surgical approach with the aid of intraoperative microscopy and fiberoptics to perform apicoectomy in the palatal root of maxillary first molars.

In this study, maxillary sinuses were present on this route in almost half of patients. For precise planning of endodontic surgery, it is crucial to determine the exact dimensions and locations of periapical lesions, as well as their relationship with the roots and other neighboring anatomic structures. Precise determination of bone thickness and the exact location of anatomic structures in relation to the lesion allows for adequate surgical planning, assuring a more predictable outcome..$^{28,29}$

Thus, CBCT seems indispensable to case selection and planning for endodontic surgery. The thickness of the cortical plate, the cancellous bone pattern, fenestrations, and the inclination of the roots of the teeth planned to undergo periapical surgery are able to be determined preoperatively. The roots of the maxillary posterior teeth and their periapical tissues can be visualized separately and in all three orthogonal planes without superimposition of the overlying zygomatic buttress, alveolar bone, or adjacent roots. The spatial relationship of the roots of multirooted teeth can be visualized in three dimensions. ${ }^{30}$

Although the present study demonstrated that CBCT is a superior diagnostic tool for identification of a vestibular surgical pathway, it should be stated that CBCT images should not necessarily replace conventional radiographic images when there is no need for a surgical procedure to eliminate infected tissues by resecting the root apices. CBCT studies cause higher radiation exposure 14-20 times greater). From the standpoint of radiation risk, CBCT appears to have three to seven times the risk of a panoramic examination depending on the area examined, degree of collimation, and acquisition software version. Thus, selection of an imaging modality for diagnostic and surgical purposes, as in this study, should be based on the diagnostic yield expected and should be in accordance with the "As Low As Reasonably Achievable" (ALARA) principle. ${ }^{15,31,32}$

Based on the findings in this study, we strongly recommend $\mathrm{CBCT}$ imaging before planning endodontic surgery of the palatine root of maxillary molars. It seems reasonable to use vestibular access in proper cases. Further studies should be performed to evaluate the benefits of this imaging modality.

In conclusion, for precise planning of endodontic surgery, it is crucial to determine the exact dimensions and locations of periapical lesions, as well as their relationship with the roots and other neighboring anatomic structures. CBCT can be a powerful tool for the evaluation of surgical cases with accurate measurements in all three dimensions and less ionizing radiation to avoid complications during surgery.

\section{REFERENCES}

1. Walton RE, Torabinejad M. Endodontic Surgery. Principles and Practice of Endodontics ed. 3 W.B.Saunders Company 2002:425-426.

2. Oberli K, Bornstein MM, von Arx T. Periapical surgery and the maxillary sinus: radiographic parameters for clinical outcome. Oral Surg Oral Med Oral Pathol Oral Radiol Endod 2007; 103:848-853.

3. Ioannides C, Borstlap WA Apicoectomy on molars: a clinical and radiographical study. Int J Oral Surg 1983;12:73-79.

4. Gutmann JL, Harrison JW. Posterior endodontic surgery: anatomical considerations and clinical techniques. Int En$\operatorname{dod} J 1985 ; 18: 8-34$

5. Rigolone M, Pasqualini D, Bianchi L, Berutti E, Bianchi SD. Vestibular surgical access to the palatine root of the superior first molar: "low-dose cone-beam" CT analysis of the pathway and its anatomic variations. J Endod 2003;29:773775.

6. Wallace JA. Transantral endodontic surgery. Oral Surg Oral Med Oral Pathol Oral Radiol Endod 1996;82:80-83.

7. Sicher H, DeBrul EL. Oral Anatomy 6th ed. St. Louis:CV Mosby Co. 1975.

8. Arens DE, Adams WR, DeCastro RA. Endodontic Surgery. Philadelphia: Harper and Row, 1981.

9. Patel S, Dawood A, Ford TP, Whaites E. The potential applications of cone beam computed tomography in the management of endodontic problems. Int Endod J 2007;40:818-830.

10. Cotton TP, Geisler TM, Holden DT, Schwartz SA, Schindler WG. Endodontic applications of cone-beam volumetric tomography. J Endod. 2007;33:1121-1132. 
11. Patel S. New dimensions in endodontic imaging: Part 2. Cone beam computed tomography. Int Endod J 2009;42:463475.

12. Patel S, Dawood A, Whaites E, Pitt Ford T. New dimensions in endodontic imaging: part 1. Conventional and alternative radiographic systems. Int Endod $J$ 2009;42:447-462.

13. Mozzo P, Procacci C, Tacconi A, Martini PT, and Bergamo IA. A new volumetric CT machine for dental imaging based on the cone-beam technique: preliminary results. Eur Radiol 1998;8:1558-1564.

14. Siqueira JF Jr. Aetiology of root canal treatment failure: why well-treated teeth can fail. Int Endod $J$ 2001;34:1-10.

15. Nair PN, Sjogren U, Figdor D, Sundqvist G. Persistent periapical radiolucencies of root-filled human teeth, failed endodontic treatments, and periapical scars. Oral Surg Oral Med Oral Pathol Oral Radiol Endod 1999;87:617-627.

16. Sundqvist G, Figdor D, Persson S, Sjogren U. Microbiologic analysis of teeth with failed endodontic treatment and the outcome of conservative re-treatment. Oral Surg Oral Med Oral Pathol Oral Radiol Endod 1998;85:86-93.

17. Ferreira FB, Ferreira AL, Gomes BP, Souza-Filho FJ. Resolution of persistent periapical infection by endodontic surgery. Int Endod J 2004;37:61-69.

18. Reit C, Petersson K, Molven 0. Diagnosis of pulpal and periapical disease. Textbook of endodontology, ed. 1. Oxford UK: Blackwell Publishing Ltd, 2003:9-18.

19. Low KM, Dula K, Bürgin W, von Arx T. Comparison of periapical radiography and limited cone-beam tomography in posterior maxillary teeth referred for apical surgery. $J$ Endod 2008;34:557-562.

20. Orhan K, Aksoy U, Kalender A. Cone-beam computed tomographic evaluation of spontaneously healed root fracture. J Endod 2010;36:1584-1587.

21. Huumonen S, Kvist T, Gröndahl K, Molander A. Diagnostic value of computed tomography in re-treatment of root fillings in maxillary molars. Int Endod $J$ 2006;39:827-833.

22. Jin GC, Kim KD, Roh BD, Lee CY, Lee SJ. Buccal bone plate thickness of the Asian people. J Endod 2005;31:430-434.

23. Jun BC, Song SW, Park CS, Lee DH, Cho KJ, Cho JH. The analysis of maxillary sinus aeration according to aging process; volume assessment by 3-dimensional reconstruction by high-resolutional CT scanning. Otolaryngol Head Neck Surg 2005;132:429-434.

24. Ariji Y, Kuroki T, Moriguchi S, Ariji E, Kanda S. Age changes in the volume of the human maxillary sinus: a study using computed tomography. Dentomaxillofac Radiol 1994;23:163168.

25. Wishart JM, Need AG, Horowitz M, Morris HA, Nordin BE. Effect of age on bone density and bone turnover in men. Clin Endocrinol 1995;42:141-146.
26. Meier DE, Orwoll ES, Keenan EJ, Fagerstrom RM. Marked decline in trabecular bone mineral content in healthy men with age: lack of association with sex steroid levels. $J \mathrm{Am}$ Geriatr Soc 1987;35:189-197.

27. Freedman A, Horowitz I. Complications after apicoectomy in maxillary premolar and molar teeth. Int J Oral Maxillofac Surg 1999;28:192-194.

28. Hirsch JM, Ahlström U, Henrikson PA, Heyden G, Peterson LE. Periapical surgery. Int J Oral Surg 1979;8:173-185.

29. Williams MY, Mealey BL, Hallmon WW. The role of computerized tomography in dental implantology. Int J Oral Maxillofac Implants 1992;7:373-380.

30. Nakata K, Naitoh M, Izumi M, Inamoto K, Ariji E, Nakamura $H$. Effectiveness of dental computed tomography in diagnostic imaging of periradicular lesion of each root of a multirooted tooth: a case report. J Endod 2006;32:583-587.

31. Angelopoulos C, Thomas SL, Hechler S, Parissis N, Hlavacek M. Comparison between digital panoramic radiography and cone-beam computed tomography for the identification of the mandibular canal as part of presurgical dental implant assessment. J Oral Maxillofac Surg. 2008;66: 21302135.

32. Ludlow JB, Davies-Ludlow LE, Brooks SL. Dosimetry of two extraoral direct digital imaging devices: NewTom cone beam CT and Orthophos Plus DS panoramic unit. Dentomaxillofac Radiol. 2003;32:229-234. 